УДК 378

$10.17213 / 2075-2067-2020-4-22-30$

\title{
ИСПОЛЬЗОВАНИЕ ИННОВАЦИОННЫХ И ДИСТАНЦИОННЫХ ТЕХНОЛОГИЙ В УЧЕБНОМ ПРОЦЕССЕ ВЫСШЕЙ ШКОЛЫ
}

\author{
(C) 2020 г. А. В. Мирочниченко , И. Н. Алексеенко**, Э. Н. Гаглоева *** \\ *Южжный федеральный университет, г. Ростов-на-Дону, Россия \\ **Донской педагогический колледж, г. Ростов-на-Дону, Россия \\ ***Юго-Осетинский государственный университет имени А. Тибилова, \\ 2. Цхинвал, Республика Южная Осетия
}

Целью исследования является анализ применения инноваџионных и дистанционных технологий в учебном прочессе высшей школы в современных условиях системных преобразований.

Методологическая база исследования основополагается на теоритических посылах педагогической инноватики и практических методах инновациионного и дистанционного обучения.

Результаты исследования. Написание этой статьи вызвано глубоким интересом $\kappa$ происходящим изменениям в сфере высшего образования и потребностью осмысления использования инновационных и дистанционных технологий в учебном процессе высшей школь. В статье представлены современные инноваџионные педагогические технологии, применяемые в учебном процессе высшей школь: технология обучения в сотрудничестве, технология проектов, технология проблемного обучения, технология компьютерного обучения, технология дистанционного обучения; кроме того, проводится компаративный анализ между традиционной технологией и личностно ориентированным обучением.

Перспективу исследования составляет дальнейшее исследование современного учебного процесса с использованием инновационных педагогических технологий наряду с традищионными, способствующими личностному и профессиональному росту студенческой молодежи.

Ключевые слова: инновачионные образовательные технологии; дистанциионные технологии; учебный процесс; высшая школа; технология обучения в сотрудничестве; технология проектов; технология проблемного обучения; технология компьютерного обучения.

\section{THE USE OF INNOVATIVE AND DISTANCE TECHNOLOGIES IN THE EDUCATIONAL PROCESS OF HIGHER EDUCATION}

\author{
(C) 2020 A. V. Miroshnichenko*, I. N. Alekseenko**, E. N. Gagloeva*** \\ *Southern Federal University, Rostov-on-Don, Russia \\ **Don Pedagogical College, Rostov-on-Don, Russia \\ ***A. Tibilov South Ossetian State University, Tskhinvali, Republic of South Ossetia
}

The purpose of the study is an analysis of the application of innovative and distance technologies in the educational process of higher education in modern conditions of systemic transformations. 
The methodological base of the study is based on the theoretical premises of pedagogical innovation and practical methods of innovative and distance learning.

The results of the study. This article was written because of the deep interest in the ongoing changes in the field of higher education and the need to comprehend the use of innovative and distance technologies in the educational process of higher education. The article presents modern innovative pedagogical technologies used in the educational process of higher education: technology of teaching in cooperation, technology of projects, technology of problem learning, technology of computer learning, technology of distance learning; in addition, a comparative analysis is carried out between traditional technology and student-centered learning.

The prospect of the study is further research of the modern educational process using both traditional and innovative pedagogical technologies that contribute to the personal growth of student youth.

Key words: innovative educational technologies; distance technologies; educational process; higher education; collaborative learning technology; project technology; problem learning technology; computer learning technology.

Введение. Смена парадигмы высшего образования, системные преобразования, о необходимости которых в последнее время все чаще говорят на разных уровнях, имеют непосредственное отношение, в первую очередь, к учебно-образовательным процессам $[1,2]$. Инновационный характер учебно-образовательных технологий, применяемых в организации учебного процесса высшей школы, является важным инструментом конкурентоспособности высших учебных заведений в современных динамичных условиях, поэтому, по мнению многих специалистов, существует настоятельная необходимость и важность внедрения инновационных технологий обучения (в том числе и компьютерных, дистанционных), альтернативных традиционным технологиям, ибо «внедрение инноваций в образовательную деятельность в конечном счете приведет к повышению качества подготовки будущих специалистов, бакалавров и магистров» [3].

Термин «инновация» имеет латинское происхождение и в переводе обозначает изменение, обновление, проще говоря, введение нового, прогрессивного. Понятие «социальная инновация» определяется как «сознательно организуемое нововведение в практике общественной работы, которое формируется в соответствии с изменяющимися общественными условиями и имеет целью эффективные преобразования в социальной сфере» [4].
Что же касается педагогической интерпретации, то категория «инновация» обозначает нововведение, улучшающее протекание и результаты учебно-воспитательного и образовательного процесса. Как подчеркивает О.А. Новикова, инновацию в обучении можно рассматривать и как процесс (масштабное или частичное изменение системы и соответствующую деятельность), и как продукт (результат) этой деятельности [5].

Теоретическим осмыслением педагогических инноваций занимается новая отрасль педагогического знания - инновационные педагогические технологии, представляющие собой, согласно определению И. М. Дичковской, «целеустремленное, систематическое и последовательное внедрение в практику оригинальных, новаторских способов, приемов педагогических действий и способов, которые охватывают целостный учебный процесс от определения его цели до желаемых результатов» [6].

Среди современных педагогических технологий, ориентированных на инновационные и дистанционные технологии, применяемых в учебном процессе высшей школы, значительный интерес для обучения студентов представляют те, которые нацелены на групповую работу, обучение студентов в сотрудничестве, на технологию компьютерного обучения для работы с разными источниками информации [7]. 
Инновационные технологии, используемые в учебном процессе высшей школы. Исследователи проблем педагогической инноватики отмечают, что большинство инновационных технологий являются личностно ориентированными [8]. С целью более точного представления специфики инновационных технологий, применяемых в учебном процессе высшей школы, целесообразно сравнить традиционную технологию с личностно ориентированной (таблица 1).

Разумеется, не стоит совсем отказываться от традиционной технологии обучения, ибо она является фундаментом знаний, т.е. позволяет получать фундаментальные знания, но сегодня целесообразно также применять в учебном процессе и элементы инновационных технологий.

На данном этапе функционирования высшей школы существует немало инновационных и дистанционных технологий, которые активно применяются в учебном процессе. К такого рода технологиям относятся: технология обучения в сотрудничестве, технология проектов, технология проблемного обучения, технология компьютерного обучения, технология дистанционного обучения и другие интерактивные технологии.

При этом стоит заметить, что элементы большинства упомянутых технологий пре-

подаватели весьма активно и достаточно эффективно используют в ходе учебного процесса. Однако на некоторые инновационные и дистанционные технологии следует обратить внимание и в рамках данной публикации привести их описание.

Одной из инновационных технологий является технология обучения в сотрудничестве, появившаяся как альтернативный вариант традиционной системе образования. В рамках данной технологии объединены три идеи: обучение в коллективе, взаимная оценка, работа в малых группах [9]. Обучение в сотрудничестве позволяет студентам работать совместно, коллективно конструировать и продуцировать новые знания, не потребляя их в уже готовом виде.

Во время обучения в сотрудничестве решаются определенные задачи, в частности: 1)студентом лучше воспринимается материал, если он умеет устанавливать контакты с другими членами группы; 2) от умения устанавливать контакты, общаться с другими членами группы зависит и умение студентов грамотно формулировать и выражать свои мысли; 3) в процессе социальных контактов между студентами образуется сообщество людей, которые владеют определенными знаниями и готовы получать новые знания

Таблица 1

\section{Сравнение традиционной технологии с личностно ориентированным обучением}

\begin{tabular}{|c|c|c|}
\hline Параметры & Традиционная технология & Личностно ориентированное обучение \\
\hline $\begin{array}{l}\text { Философия } \\
\text { образования }\end{array}$ & \begin{tabular}{|l|} 
В центре обучения - препода- \\
ватель. Студент - объект обуче- \\
ния. Обучение рассматривается \\
как результат, базируется на \\
принципах соревнований. Ори- \\
ентир на внешнюю мотивацию. \\
\end{tabular} & $\begin{array}{l}\text { В центре обучения - студент, он является } \\
\text { субъектом учебного процесса. Обучение } \\
\text { рассматривается как процесс. Стимулиру- } \\
\text { ется сотрудничество и взаимопомощь. Ори- } \\
\text { ентир на внутреннюю мотивацию. }\end{array}$ \\
\hline Цели & $\begin{array}{l}\text { Внимание акцентируется только } \\
\text { на формальных знаниях, умени- } \\
\text { ях и навыках. }\end{array}$ & $\begin{array}{l}\text { Внимание акцентируется на отношении } \\
\text { к знаниям, умениям, навыкам, которые } \\
\text { используются в настоящее время и в буду- } \\
\text { щем. Заключается в корреляции знаний, } \\
\text { умений и навыков, отношении к обучению. }\end{array}$ \\
\hline Методика & $\begin{array}{l}\text { Внимание концентрируется на } \\
\text { отображении выученного содер- } \\
\text { жания. Ориентир на среднего } \\
\text { студента. }\end{array}$ & $\begin{array}{l}\text { Обучение осуществляется на основе твор- } \\
\text { ческих методов. Ориентир на коллектив- } \\
\text { ную и индивидуальную деятельность в } \\
\text { малых группах с целью формирования у } \\
\text { студентов коммуникативных навыков. }\end{array}$ \\
\hline
\end{tabular}


в процессе социальной коммуникации, делиться этими знаниями [10].

Технология проектов — вторая инновационная технология (качественная альтернатива рефератам), это комплексная методика обучения, позволяющая организовать учебный процесс, исходя из личностных интересов студентов, что позволяет проявить самостоятельность в планировании, организации и контроле собственной учебно-познавательной деятельности. В основе технологии проектов лежит развитие познавательных, творческих интересов студентов, умений самостоятельно конструировать свои знания, ориентироваться в информационном пространстве, развитие критического мышления. Проектная технология направлена на самостоятельную деятельность студентов - индивидуальную, групповую, которую они выполняют на протяжении определенного отрезка времени. Итогом проектной деятельности являются учебные проекты [11]. Заметим, что данная технология органически объединяется с групповыми технологиями, с проблемным и исследовательским обучением.

При работе над проектом проводится структурирование содержательной его части с указанием поэтапных результатов и сроков презентации. Принято выделять семь этапов работы над проектом: организационный; выбор и обсуждение главной идеи, целей и задач будущего проекта; обсуждение методических аспектов и организации работы студентов; структурирование проекта с выделением подзадач для малых групп студентов, подбор необходимой информации; работа над проектом; подведение итогов, оформление результатов; презентация проекта.

Следующим видом инновационных технологий, используемых в учебном процессе высшей школы, является технология проблемного обучения, под которым подразумевается учебно-познавательная деятельность, базирующаяся на создании преподавателем и решении студентами проблемных ситуаций с целью усвоения последними новых знаний, умений и навыков. В.А. Ситаров подчеркивает, что проблемное обучение строится на аналитико-синтетической деятельности студентов, «реализуемой в рассуждении, размышлении». «Это эвристический, исследовательский тип обучения с большим развиваю- щим потенциалом» [12]. Во время проблемного обучения преподаватель не просто дает информацию в готовом виде, но ставит перед студентами проблему, заинтересовывает, вызывает у них интенцию найти способы ее решения.

Основное содержание технологий проблемного обучения составляют методы и приемы уместного использования учебных проблемных ситуаций, создание и решение учебных проблем. В целом проблемность главная закономерность процесса познания и активизации мыслительных процессов.

На сегодняшний день неотъемлемой частью учебного процесса высшей школы является инновационная технология компьютерного обучения в условиях информационной сетевой среды [13]. Бурно развивающийся прогресс в области развития персональных электронно-вычислительных машин вывел преподавателей на новую технологию компьютерного обучения [14]. Компьютеры, оснащенные специальными учебными программами, позволяют решать множество дидактических задач. Они быстро выдают определенную информацию, проверяют ответы студентов, открывают доступ к электронным библиотекам, к основным отечественным и зарубежным базам данных, дают возможность создания мультимедийных учебных пособий, презентаций и пр. Адаптивные программы могут приближать темп обучения к индивидуальным особенностям студентов, анализировать ответы и, опираясь на полученную информацию, устанавливать очередную часть учебного материала.

Дистанционные образовательные технологии в высшей школе. Как известно, дистанционное обучение - явление, возникшее достаточно давно, оно было ранее связано с традиционным заочным обучением, распространением корреспондентского обучения [15].

Основной специфической особенностью дистанционных образовательных технологий является осуществление процесса обучения с сохранением определенной дистанции, расстояния. В рамках дистанционного обучения средством коммуникации является сеть Интернет, взаимодействие в которой возможно как в реальном, текущем времени, так и в от- 
ставленном времени с применением электронных площадок для коммуникации и передачи информации, необходимой для изучения дисциплины [16].

Понятие «дистанционное обучение» означает такую организацию учебного процесса, при которой преподаватель разрабатывает учебную программу, главным образом базирующуюся на самостоятельном обучении студента. Такая среда обучения характеризуется тем, что студент, как правило, отделен от преподавателя в пространстве или во времени, в то же время студенты и преподаватели имеют возможность осуществлять диалог посредством телекоммуникации.

Дистанционное обучение позволяет учиться жителям регионов, где нет иных возможностей для профессиональной подготовки или качественного высшего образования, нет университета нужного профиля или преподавателей требуемого уровня квалификации [17].

Основу учебного процесса при дистанционном обучении составляет «целенаправленная и контролируемая интенсивная самостоятельная работа студента» [18], поскольку он имеет возможность осуществлять учебный процесс по своему индивидуальному расписанию, в удобное время и удобном для себя месте, что способствует так или иначе субъектности личности [19]. Ключевым понятием дистанционных технологий, используемых в учебном процессе высшей школы, является понятие «интерактивность» - целенаправленное и систематическое взаимодействие преподавателя и студента, а также студентов между собой, т. е. интерактивное взаимодействие субъектов образовательного процесса.

Дистанционное образование неотъемлемо от развития в вузе информационно-коммуникационных технологий на всех уровнях организационно-управленческого процесса. Именно уровень использования новейших сетевых технологий в процессе обучения и определяет тот «водораздел», который проходит между традиционным заочным и современным дистанционным обучением [20].

Заключение. Современное образование в высшей школе с использованием инновационных педагогических технологий наряду с традиционными технологиями должно спо- собствовать личностному росту студенческой молодежи. В ходе учебного процесса необходимо дать возможность каждому студенту обрести себя, дать возможность для творческого роста и развития, обеспечить успех в освоении учебного материала, создать условия для формирования будущего профессионала в конкретной сфере. Специфика современного обучения заключается в развитии креативного потенциала личности всякого студента, стимулировании свободы выбора содержания и темпа обучения, создании комфортных условий для каждого студента, партнерских отношений между субъектами образовательного процесса, комплексного решения образовательных, развивающих и воспитательных задач.

\section{Литература}

1. Gafiatulina N.K., Makadey L.I., Gluzman I. V., Lozhechkina A.D., Volkova L.A., Bandurin A.P. The role of health-saving technologies in the process of students educational and professional socialization. EurAsian Journal of BioSciences. - 2019. - Vol. 13. - №2. Pp. 1557-1563.

2. Колесина К.Ю., Мирошниченко А.В. Проблемы педагогических инноваций в современном образовании // Северо-Кавказский психологический вестник. - 2014. T. 12. - №4. - C. 34-39.

3. Оганнисян Л. А., Ступак Н. Н. Инновационные технологии в образовательном процессе вуза // Таврический научный обозреватель. - 2015. - №2. - С. 105-108.

4. Гафиатулина Н.Х. Социальное здоровье молодежи в контексте современных инноваций в российском обществе // Инновационная наука и современное общество: сб. статей междунар. научно-практ. конф. Уфа, 2015. - С. 149-153.

5. Новикова О.А. Использование инновационных технологий в учебном процессе // Известия на съюза на учените - сливен. Национаналната конференция с международно участие «образовательни технологии 2013» проведена на 13-15 септември 2013 в гр. Каварна. - С. 265-269.

6. Дичковская И. М. Инновационные педагогические технологии. - К.: Академвидав, 2004. - 352 c. 
7. Руденко А.М., Самыгин С.И., Алексеенко И.Н., Бондин В.И., Васьков М.А., Kотлярова В.В., Шевченко А.М., Гончарова Н.Г. Педагогика: курс лекций. Сер. Зачёт и экзамен. - Ростов-на-Дону, 2020.

8. Сиротюк А.Л., Сергеева М.Г. Инновационный подход к обучению в профессиональной школе: монография. - Курск, 2011. - $231 \mathrm{c}$.

9. Полат Е.С. Современные педагогические и информационные технологии в системе образования. - М., 2010. - 368 с.

10. Gryshai V., Gafiatulina N., Kasyanov V., Velikodnaya I., Kosinov S., Lyubetsky N., Samygin S. Social Health of Youth in the Context of Migration Processes in Russia: Assessment of the Threat to National Security // Вісник Національної академії керівних кадрів культури і мистецтв. - 2018. - №2. - С. 141-145.

11. Бтемирова Р. И. Метод проектов в условиях современного высшего образования // [Электронный ресурс] Современные проблемы науки и образования. - 2016. - №3. РЕЖИМ ДОСТУПА: https://www.scienceeducation.ru/ru/article/view?id=24488.

12. Ситаров В.А. Проблемное обучение как одно из направлений современных технологий обучения // Знание. Понимание. Умение. - 2009. - №1. - С. 148-157.

13. Охрименко Е.И. Особенности дистанционного обучения в высшей школе: методы и технологии образования / Х Международная научно-методическая конференция «Новые образовательные технологии в вузе». [Электронный ресурс]. - Екатеринбург, 2013. - Режим доступа: http://hdl.handle. net/10995/26597.

14. Гафиатулина Н.Х., Рачипа А.В., Самысин С.И. Информационная сетевая среда как фактор влияния на социальное здоровье российской студенческой молодежи // Гуманитарные, социально-экономические и общественные науки. - 2018. - №1. - С.23-27.

15. Гафиатулина Н.Х., Касьянов В.В., Самыгин П.С., Самылин С.И. Российское общество в условиях самоизоляции. Социальные эффекты и последствия пандемии covid-19. Монография. - Москва, 2020.

16. Толстоухова И.В. Дистанционное обучение как современная педагогическая технология // Человек и образование. 2016. — №2 (47). - C. 98-100.
17. Девтерова 3. Р. Методология реализации систем дистанционного обучения // Сибирский педагогический журнал. - 2010. №1. - С. 31-39.

18. Алексеенко И.Н. Содержание теоретической модели становления и развития профессионально-педагогической субъектности личности // Известия высших учебных заведений. Северо-Кавказский регион. Общественные науки. — 2017. — №1 (193). C. 4-8.

19. Psikhologicheskie issledovaniya informacionnoy kulyuri i osobennosty chennostnosmaslovoy sfery studentov, rabotaushih s informacionnima technologiyami. North-Caucasian // Психологический журнал. — 2009. - №3. C. 38 .

20. Коломейченко А.C. Дистанционные технологии в высшей школе // Актуальные проблемы гуманитарных и естественных наук. - 2013. - №9. - С. 206-208.

\section{References}

1. Gafiatulina N.K., Makadey L.I., Gluzman I. V., Lozhechkina A.D., Volkova L.A., Bandurin A.P. The role of health-saving technologies in the process of students educational and professional socialization. EurAsian Journal of BioSciences. - 2019. - Vol. 13. - №2. Pp. 1557-1563.

2. Kolesina K. Ju., Miroshnichenko A.V. Problemy pedagogicheskih innovacij v sovremennom obrazovanii [Problems of pedagogical innovations in modern education] // SeveroKavkazskij psihologicheskij vestnik [NorthCaucasian psychological Bulletin]. — 2014. Vol. 12. - №4. - Pp. 34-39.

3. Ogannisjan L.A., Stupak N.N. Innovacionnye tehnologii $\mathrm{v}$ obrazovatel'nom processe vuza [Innovative technologies in the educational process of the University] // Tavricheskij nauchnyj obozrevatel' [Tavrichesky scientific reviewer]. - 2015. - №2. - Pp. 105-108.

4. Gafiatulina N.H. Social'noe zdorov'e molodezhi v kontekste sovremennyh innovacij v rossijskom obshhestve [Social health of young people in the context of modern innovations in Russian society] // Innovacionnaja nauka i sovremennoe obshhestvo: sb. statej mezhdunar. nauchno-prakt. konf. [Innovative science and modern society: collection of international 
articles. scientific and practical conf.]. - Ufa, 2015. - Pp. 149-153.

5. Novikova O.A. Ispol'zovanie innovacionnyh tehnologij $\mathrm{v}$ uchebnom processe [Use of innovative technologies in the educational process]// Izvestija na sjuza na uchenite - sliven. Nacionanalnata konferencija $s$ mezhdunarodno uchastie «obrazovatel'ni tehnologii 2013» provedena na 13-15 septemvri 2013 v gr. Kavarna. - Pp. 265-269.

6. Dichkovskaja I.M. Innovacionnye pedagogicheskie tehnologii [Innovative educational technology]. - Kiev: Akademvidav, 2004. $352 \mathrm{p}$.

7. RudenkoA.M., Samygin S.I., Alekseenko I.N., Bondin V.I., Vas'kov M. A., Kotljarova V.V., Shevchenko A.M., Goncharova N.G. Pedagogika: kurs lekcij. Ser. Zachjot i jekzamen [Pedagogy: course of lectures. Ser. The tests and exams]. - Rostov-on-Don, 2020.

8. SirotjukA.L., Sergeeva M.G. Innovacionnyj podhod k obucheniju v professional'noj shkole: monografija [Innovative approach to training in professional schools: monograph]. Kursk, 2011. - 231 p.

9. Polat E.S. Sovremennye pedagogicheskie i informacionnye tehnologii $\mathrm{v}$ sisteme obrazovanija [Modern pedagogical and information technologies in the education system]. - Moscow, 2010. - $368 \mathrm{p}$.

10. Gryshai V., Gafiatulina N., Kasyanov V., Velikodnaya I., Kosinov S., Lyubetsky N., Samygin S. Social Health of Youth in the Context of Migration Processes in Russia: Assessment of the Threat to National Security // Visnik Nacional'noï akademiï kerivnih kadriv kul'turi i mistectv. - 2018. - №2. - Pp. 141-145.

11. Btemirova R.I. Metod proektov v uslovijah sovremennogo vysshego obrazovanija [The project method in the conditions of modern higher education] // [Jelektronnyj resurs] Sovremennye problemy nauki i obrazovanija [Modern problems of science and education]. - 2016. №3. - URL: https://www.science-education.ru/ $\mathrm{ru} /$ article/view? id=24488.

12. Sitarov V.A. Problemnoe obuchenie kak odno iz napravlenij sovremennyh tehnologij obuchenija [Problem-based learning as one of the directions of modern training technologies]// Znanie. Ponimanie. Umenie [Knowledge. Understanding. Skill]. - 2009. №1. - Pp. 148-157.
13. Ohrimenko E.I. Osobennosti distancionnogo obuchenija $\mathrm{v}$ vysshej shkole: metody $\mathrm{i}$ tehnologii obrazovanija [Features of distance learning in higher education: methods and technologies of education] / X Mezhdunarodnaja nauchno-metodicheskaja konferencija «Novye obrazovatel'nye tehnologii $\mathrm{v}$ vuze». [X international scientific and methodological conference «New educational technologies in higher education»] [Jelektronnyj resurs]. Ekaterinburg, 2013. — URL: http://hdl.handle. net/10995/26597.

14. Gafiatulina N.H., Rachipa A.V., Samygin $S . I$. Informacionnaja setevaja sreda kak faktor vlijanija na social'noe zdorov'e rossijskoj studencheskoj molodezhi [Information network environment as a factor of influence on the social health of Russian students] // Gumanitarnye, social'no-jekonomicheskie i obshhestvennye nauki [Humanities, socio-economic and social Sciences]. - 2018. - №1. - Pp. 23-27.

15. Gafiatulina N.H., Kas'janov V. V., Samygin P.S., Samygin S.I. Rossijskoe obshhestvo v uslovijah samoizoljacii. Social'nye jeffekty i posledstvija pandemii covid-19. Monografija [Russian society in conditions of self-isolation. Social effects and consequences of the covid-19 pandemic. Monograph]. - Moscow, 2020.

16. Tolstouhova I. V. Distancionnoe obuchenie kak sovremennaja pedagogicheskaja tehnologija [Distance learning as a modern pedagogical technology] // Chelovek i obrazovanie [Man and education]. - 2016. - №2 (47). - Pp. 98-100.

17. Devterova Z.R. Metodologija realizacii sistem distancionnogo obuchenija [Methodology for implementing distance learning systems] // Sibirskij pedagogicheskij zhurnal [Siberian pedagogical journal]. — 2010. — №1. - Pp. 31-39.

18. Alekseenko I.N. Soderzhanie teoreticheskoj modeli stanovlenija i razvitija professional'no-pedagogicheskoj subektnosti lichnosti [The content of the theoretical model of formation and development of professional and pedagogical subjectivity of the individual]// Izvestija vysshih uchebnyh zavedenij. Severo-Kavkazskij region. Obshhestvennye nauki [News of higher educational institutions. NorthCaucasus region. Social science]. - 2017. №1 (193). - Pp. 4-8.

19. Psikhologicheskie issledovaniya informacionnoy kulyuri i osobennosty chennostnosmaslovoy sfery studentov, rabotaushih $\mathrm{s}$ infor- 
macionnima technologiyami. North-Caucasian// Psihologicheskij zhurnal [Psychological journal]. — 2009. - №3. - P. 38.

20. Kolomejchenko A.S. Distancionnye tehnologii v vysshej shkole [Distance technologies in higher education] // Aktual'nye problemy gumanitarnyh i estestvennyh nauk [Current problems of Humanities and natural Sciences]. 2013. - №9. - Pp. 206-208.
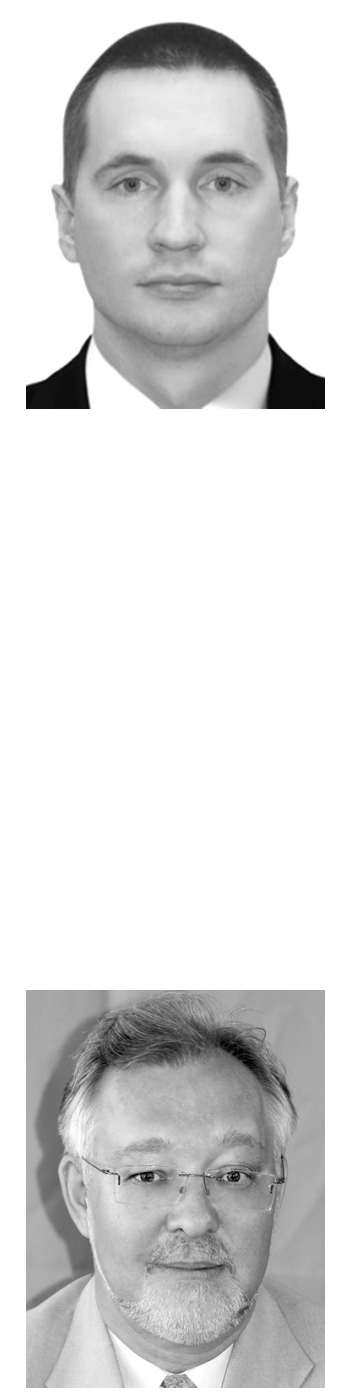

Мирошниченко Александр Владимирович - кандидат психологических наук, заведующий кафедрой общей и педагогической психологии, доцент АПП, Южный Федеральный университет.

Miroshnichenko Aleksandr Vladimirovich - Candidate of Psychological Sciences, Head of the Department of General and Educational Psychology, Associate Professor, APP, Southern Federal University.

344038 , г. Ростов-на-Дону, ул. Нагибина, 13

13 Nagibina st., 344038, Rostov-on-Don, Russia

E-mail: akmrgu@mail.ru

Алексеенко Иван Николаевич - доктор философских наук, заместитель директора по учебно-производственной работе Донского педагогического колледжа.

Alekseenko Ivan Nickolaevich - Doctor of Philosophical Sciences, Deputy Director for Training and Productive Work, Don Pedagogical College.

344023, г. Ростов-на-Дону, пр. Ленина, 92

92 Lenina av., 344023, Rostov-on-Don, Russia

E-mail: otdel_praktiki_dpk@mail.ru_ 


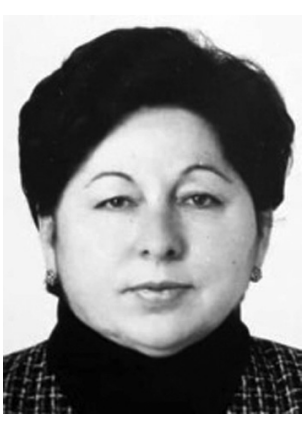

Гаглоева Эвелина Николаевна - кандидат технических наук, доцент кафедры инженерно-технических дисциплин, ЮгоОсетинский государственный университет имени А. Тибилова.

Gagloeva Evelina Nikolaevna - Candidate of Engineering Sciences, Associate Professor of the Department of Engineering and Technical Disciplines, Tibilov South Ossetian State University.

100001, Республика Южная Осетия, г. Цхинвал, ул. Путина (Московская), 8 8 Putin (Moskovskaya) st., 100001, Tskhinval, Republic of South Ossetia E-mail:0654363@mail.ru 